\title{
Determination of Gentamicin Sulphate Composition and Related Substances in Pharmaceutical Preparations by LC with Charged Aerosol Detection
}

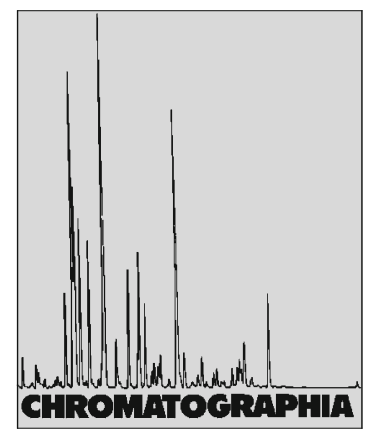

2010, 72, 1225-1229

\author{
Karolina Stypulkowska ${ }^{1}$, Agata Blazewicz ${ }^{1, 凶}$, Zbigniew Fijalek $^{1,2}$, Katarzyna Sarna ${ }^{1}$ \\ ${ }^{1}$ Department of Pharmaceutical Chemistry, National Medicines Institute, 30/34 Chełmska Street, 00-725 Warsaw, Poland; \\ E-Mail: ablazewicz@il.waw.pl \\ 2 Department of Bioanalysis and Drug Analysis, Warsaw Medical University, 1 Banacha Street, 02-097 Warsaw, Poland
}

Received: 30 June 2010 / Revised: 19 August 2010 / Accepted: 31 August 2010

Online publication: 1 October 2010

\begin{abstract}
A new, simple and repeatable liquid chromatography method with charged aerosol detection (LC-CAD) for the determination of gentamicin sulphate composition and related substances has been developed. Gentamicin lacks of chromophores, therefore its determination is quite problematic. Using a universal CAD enables to achieve good separation without sample derivatization. Mass spectrometry was employed to confirm the LC-CAD peak profile. The proposed method was validated and applied for the determination of gentamicin sulphate composition and related substances in pharmaceutical preparations.
\end{abstract}

\section{Keywords}

Column liquid chromatography

Charged aerosol detection

Gentamicin sulphate

Sisomicin sulphate

\section{Introduction}

Gentamicin sulphate is an aminoglycoside antibiotic formulated by fermentation of Micromonospora purpurea [1], used in therapy against Gram-negative bacteria [2]. It is a mixture of compounds, the major components are gentamicins C1, C1a, C2, C2a and a minor one $\mathrm{C} 2 \mathrm{~b}$. Also, the related substances like sisomicin, garamine, gentamicin B1, 2-deoxystreptamine are formed in small amounts during fermentation [3, 4]. Although all are structurally similar, the antimicrobial potency as the toxicity are different, so there is strong need to control the amount of main components as well as the related substances in commercial samples.

Gentamicin's high polarity, non-volatility and lack of chromophore make the chromatographic analysis quite problematic. European Pharmacopoeia 6.8. (Ph. Eur. 6.8.) recommends LC with pulsed electrochemical detection (LCPED) [5], however, this method possesses problems with reproducibility, separation and robustness. Few improvements of LC-PED have been published [6-9], but still it is not reproducible enough. Thus other methods, direct and indirect, have been proposed. The indirect methods required pre- or post-column derivatization with either UV [10-13] or fluorescence detection [14-17] or CE [18, 19], were time consuming, tedious and not accurate enough. Direct methods included detection techniques such as refractive index (RI) [20], ELSD [21, 22], CAD [23], CE [24], ED [25, 26] or MS [27-29]. The advantages and disadvantages of these methods were discussed in $[7,23,30]$. And only few methods for the related substances determination have been reported [7, 18, 21, 23, 31].

The aim of this work was to develop a quick, simple, relatively sensitive and repeatable LC-CAD method without derivatization for the determination of five specified gentamicin sulphate components: $\mathrm{Cl}, \mathrm{Cla}$, $\mathrm{C} 2, \mathrm{C} 2 \mathrm{a}$ and $\mathrm{C} 2 \mathrm{~b}$ and related substances, which could be applied for routine analysis of these compounds in substance and in pharmaceutical preparations.

Although recently a similar application has been reported [23] there are a few 


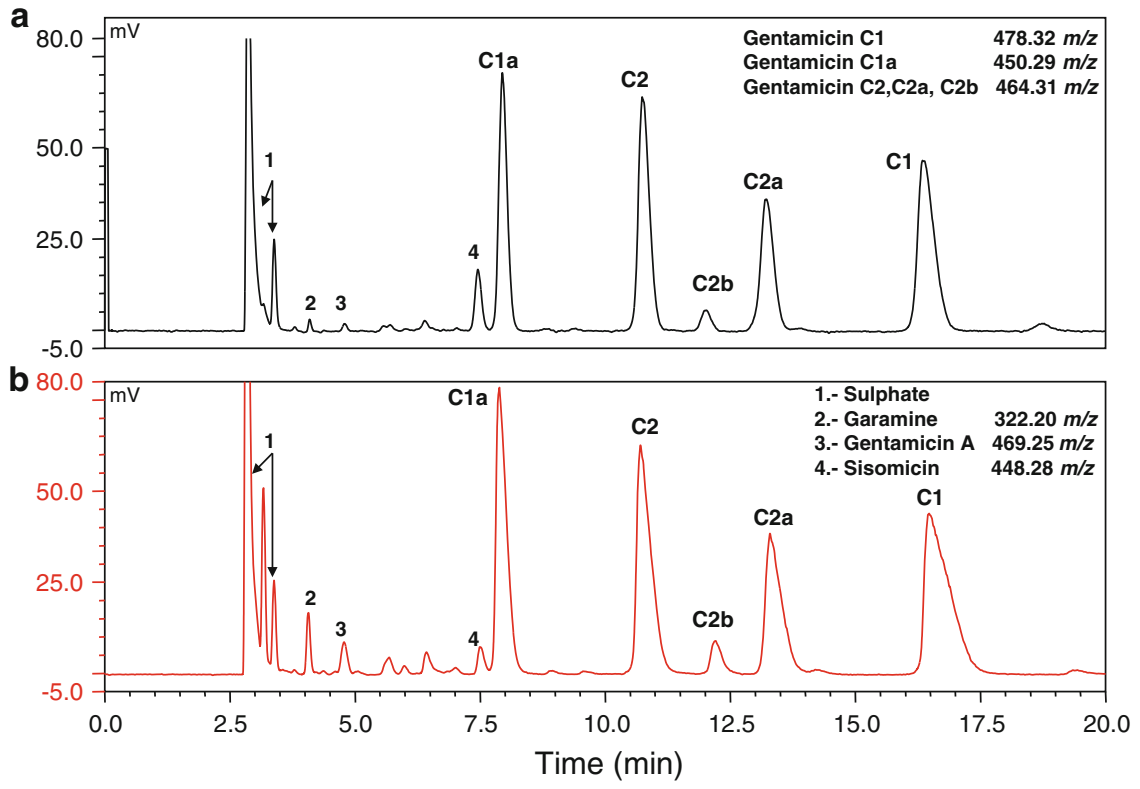

Fig. 1. LC-CAD chromatogram of the artificial mixture containing $200 \mu \mathrm{g} \mathrm{mL}^{-1}$ gentamicin and $3 \mu \mathrm{g} \mathrm{mL}^{-1}$ of sisomicin (a) and the solution containing $250 \mu \mathrm{g} \mathrm{mL}^{-1}$ gentamicin in pharmaceutical preparation (b). $m / z$ of protonated molecule from MS scan evaluated in the same chromatographic conditions

differences which make this method more reproducible. Instead of a short pentafluorophenyl column used in the mentioned application, in this work a more common $\mathrm{C} 18$ column was used successfully. The analysis time is almost two times shorter and only one mobile phase is used. In contrast to the previous application this method was successfully applied to the pharmaceuticals from different manufacturers, not only to one specific product. Also, the optimized chromatographic conditions in LC-CAD have been applied straightforward to LC-ESI-MS analysis for peaks identification.

The proposed LC-CAD method also has a few advantages over the LC-PED compendial method [5]. The most important is that the peaks due to all gentamicin components are completely resolved, as well as the peaks due to the related substances, eluting before gentamicin Cla. In addition, the peak symmetry is almost ideal and analysis time is over three times shorter.

All above mentioned reasons show the proposed method with Corona CAD is suitable for the purpose of this work. The Corona CAD is a new type of detector [32, 33] introduced for LC applications and has recently become widely employed in pharmaceutical analyses [34-40].

\section{Experimental}

\section{Chemicals and Materials}

All reagents were LC grade. Acetonitrile and methanol were from Labscan, trifluoroacetic acid (TFA) from AppliChem, formic acid (FA) from Park Scientific. Doubly distilled water additionally purified in the nanopure diamond UV deionization system from Barnstead was used throughout. Reference standards: Gentamicin sulphate and sisomicin sulphate from EDQM. Pharmaceutical preparations: Gentamicin USP, a solution for injections from KRKA (Novo Mesto, Slovenia) and Gentamicin, a solution for injections from Polfa Tarchomin (Warsaw, Poland), both containing $40 \mathrm{mg} \mathrm{mL}^{-1}$ of gentamicin.

\section{Equipment and Conditions}

An LC Ultimate 3000 Dionex system consisting of: a pump, a degasser, an autosampler, a column heater and a pulse damper coupled with an ESA Corona CAD instrument was used. CAD response range was $100 \mathrm{pA}$, no filter selected. Nitrogen gas from nitrogen generator, regulated at 35 psi, was introduced to the detector. Data processing was carried out with Chromeleon 6.8 and Chromeleon Validation ICH software (Dionex) and chromatographic conditions optimization with DryLab 2000 Plus software (Molnar Institute).

For peak elution order determination a mass spectrometer MicrOTOF-Q II from Bruker Daltonic was used. Chromatographic conditions for MS analysis were the same as in LC-CAD. The MS settings were: electrospray ionization (ESI) in the positive ion mode, dry gas (nitrogen) flow rate $8.0 \mathrm{~L} \mathrm{~min}^{-1}$, the dry heater $180{ }^{\circ} \mathrm{C}$, the capillary voltage $4,500 \mathrm{~V}$ and end plate offset $-500 \mathrm{~V}$. MS data were recorded in full scan mode (from 50 to $800 \mathrm{~m} / \mathrm{z}$ ).

\section{Standard Solutions Preparation}

The standards of analyzed substances were accurately weighed into volumetric flasks and dissolved with the $55 \mathrm{mM}$ TFA (solvent) to produce stock solutions, which were successively diluted with the solvent to obtain required concentrations.

\section{Sample Solutions Preparation}

The concentrations of gentamicin in sample solutions were: ca. $200 \mu \mathrm{g} \mathrm{mL}^{-1}$ for determination of gentamicin sulphate composition and ca. $500 \mu \mathrm{g} \mathrm{mL}^{-1}$ for determination of impurities. All dilutions were made in $55 \mathrm{mM}$ TFA.

\section{Results and Discussion}

\section{Method Development}

The hydrophilic nature of gentamicin demands the use of highly aqueous mobile phase with addition of an ionpair agent. The different water-methanol mobile phases with addition of TFA or FA in water in isocratic and gradient 
elution modes were investigated. Isocratic condition and TFA addition were suitable for satisfactory peak separation. The content of methanol and TFA in the mobile phase was optimized using DryLab. The best resolution was obtained with a Hypersil Gold C18 analytical column $(150 \times 4.6 \mathrm{~mm} ; 3 \mu \mathrm{m})$ from Thermo Scientific in isocratic mode with the mobile phase consisting of $55 \mathrm{mM}$ TFA:methanol:acetonitrile (98:1:1, $v / v / v)$. To avoid column dewetting as a result of using highly aqueous mobile phase, the column was flushed with acetonitrile: water $(80: 20, v / v)$ for $20 \mathrm{~min}$ at the end of each day. The effect of different flow rates (from 0.4 to $0.6 \mathrm{~mL} \mathrm{~min}^{-1}$ ) and column temperature (from 20 to $30{ }^{\circ} \mathrm{C}$ ) on the peak resolution was studied. A flow rate was set at $0.5 \mathrm{~mL} \min ^{-1}, 25{ }^{\circ} \mathrm{C}$ were used throughout and injection volume was $10 \mu \mathrm{L}$. These conditions were optimal for the separation of five main gentamicin components and related substances with good resolution in $20 \mathrm{~min}$ (Fig. 1).

\section{Peaks Assignment}

As the standards of gentamicin components were not available, the peak elution order was determined according to LC-ESI-MS spectra and the relative proportions described in $\mathrm{Ph}$. Eur. [5]. Sisomicin was identified by the retention time of the standard. Additionally other compounds eluting before gentamicin Cla were found, two of them were identified as garamine and gentamicin A based on $[\mathrm{M}+\mathrm{H}]^{+} m / z$ value.

\section{Method Validation}

The method was validated according to ICH guidelines [41]. The data concerning method validation are summarized in Table 1. Peak areas were evaluated in the whole validation. Due to the lack of reference standard material of individual gentamicin components, series of working solutions of gentamicin sulphate standard with known total gentamicin concentration (calculated by subtraction of sulphate, impurities and water content) were used in the entire validation,

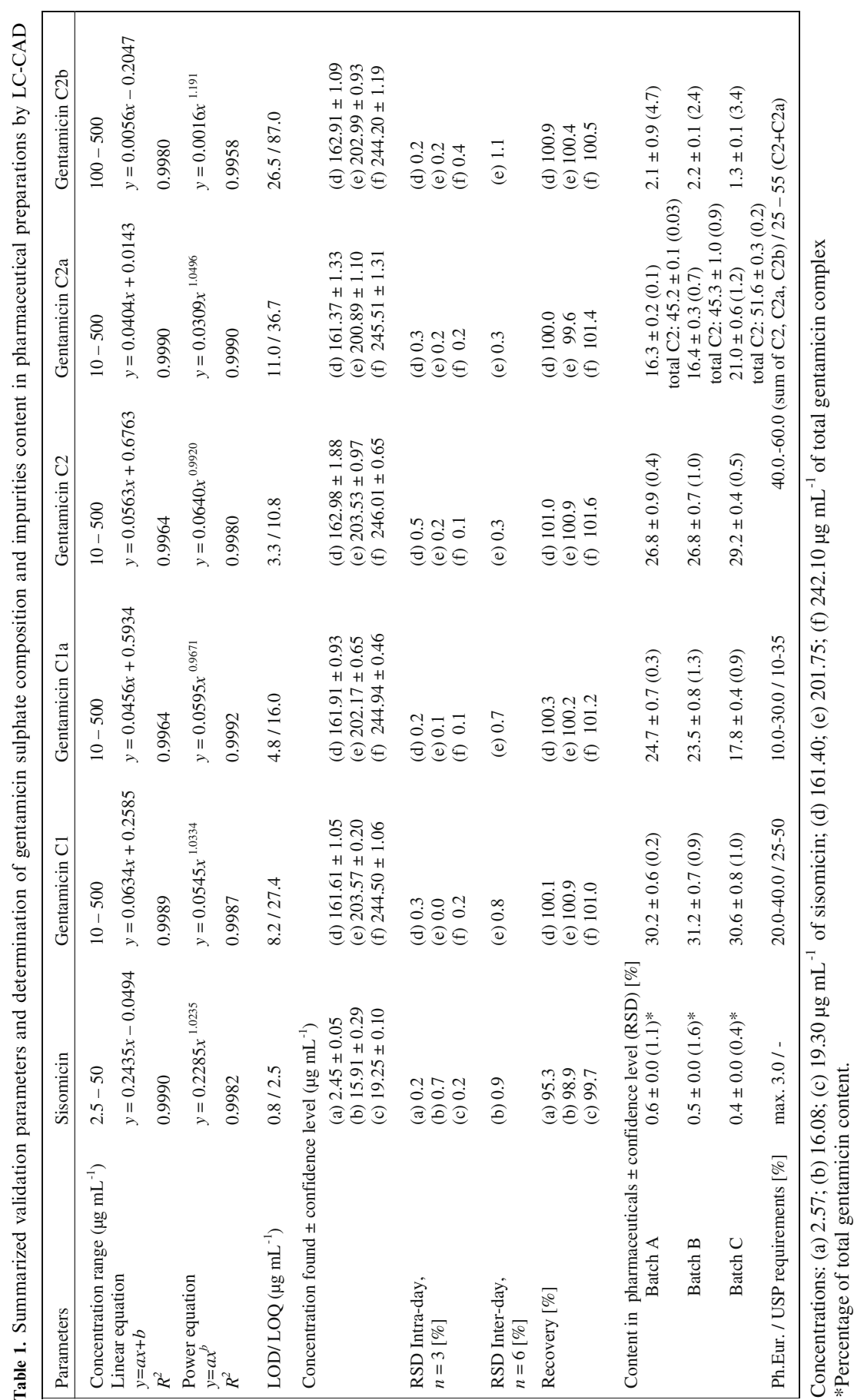

however, the peak areas of each individual component were concerned.

The linearity was estimated by analyzing gentamicin sulphate and sisomicin sulphate standards. Seven concentrations ranging from 10 to $500 \mu \mathrm{g} \mathrm{mL}^{-1}$ for gentamicin and five concentrations ranging from 2.5 to $50 \mu \mathrm{g} \mathrm{mL}^{-1}$ for sisomicin were used to obtain the calibration curves. In the ranges investigated there were no significant differences in the coefficient of determination values $\left(R^{2}\right)$ between linear and power function. Although it is known that CAD response is nonlinear at a range of four orders of magnitude, the signal is nearly linear in the smaller ranges $[42,43]$. 
The detection limit (LOD) and quantitation limit (LOQ) were defined as signal-to-noise ratio of 3:1 and 10:1.

The accuracy of the recovery and the repeatability were assessed using linear response function at three concentrations covering the specified range. The mean recoveries were in the range of 98.3$101.6 \%$. The precisions were calculated from three consecutive injections for each concentration and the observed RSD ranged from 0.04 to $0.73 \%$. Intermediate precision was calculated from 2 days.

Method robustness was evaluated during method development. Method was robust for column temperature $\pm 3{ }^{\circ} \mathrm{C}$, flow rate $\pm 20 \%$, TFA content $\pm 5 \mathrm{mM}$. For all parameter variations the minimum $R_{s}$ value between critical pair of peaks was $>1.5$.

\section{Application to Pharmaceutical Preparations}

Three pharmaceuticals from two manufacturers were investigated. From KRKA two batches: signed A and B, 3 years expired and not expired, respectively, and from Polfa batch C, 4 years expired. The excipients composition in pharmaceuticals from each manufacturer was different. Expired samples were analyzed as they were supposed to have higher impurities content.

Gentamicin sulphate composition was calculated using a normalization procedure $[5,10]$ and related substances by comparing with sisomicin sulphate standard [8].

Slight differences in the component content and in the impurities profile were observed; however, for every sample gentamicin composition was in agreement with the pharmacopoeial requirements (Table 1), as the sisomicin and other impurities content, which was less than 0.6 and $2.5 \%$, respectively, even for expired samples. RSD values were better than $2 \%$, except for gentamicin C2b described as a minor component $(1-2 \%, m / m)$.

\section{Conclusion}

The elaborate method proved to be fast, precise, accurate and sensitive and has been successfully used in analyzing commercial samples from different manufacturers. By comparison with previously developed LC methods, the improvements of this method are: short analysis time with good resolution, sensitivity and great reproducibility. Also, the optimized chromatographic conditions in LC-CAD can be applied straightforward to LC-ESI-MS analysis for peak identification which can be extremely useful as the impurities profile can differ from one another between gentamicin sulphate manufacturers. Thus this method seems to be useful for quality analysis of the substance and pharmaceutical preparations for different QC laboratories.

\section{Open Access}

This article is distributed under the terms of the Creative Commons Attribution Noncommercial License which permits any noncommercial use, distribution, and reproduction in any medium, provided the original author(s) and source are credited.

\section{References}

1. Weinstein MJ, Luedemann GM, Oden EM, Wagman GH (1963) Antimicrob Agents Chemother (Bethesda) 161:1

2. Edson RS, Terrell CL (1999) Mayo Clin Proc 74:519-528. doi:10.4065/74.5.519

3. Wagman GH, Marquez JA, Baily JA, Cooper D, Weinstein J, Tkach R, Daniels P (1972) J Chromatogr 70:171-173. doi: 10.1016/S0021-9673(01)91075-1

4. Deubner R, Schollmayer C, Wienen F, Holzgrabe U (2003) Magn Res Chem 41:589-598. doi:10.1002/mrc. 1222

5. (2008) European Pharmacopoeia ver 6.8, Monograph 01/2008:0331 corr.6.0, Council of Europe, Strasbourg, France

6. Ghinami C, Giuliani V, Menarini A, Abballe F, Travaini S, Ladisa T (2007) J Chromatogr A 1139:53-56. doi:10.1016/ j.chroma.2006.10.099

7. Manyanga V, Kreft K, Divjak B, Hoogmartens J, Adams E (2008) J Chromatogr A 1189:347-354. doi:10.1016/j.chroma. 2007.12.041

8. Pharmeuropa (2008) Vol. 20 No.4:686689, Council of Europe, Strasbourg, France

9. Cai Y-Q, Mou S-F (2005) Chinese J Chem 23:1207-1212. doi:10.1002/cjoc. 200591207

10. (2009) United States Pharmacopeia 31, Gentamicin sulfate official monograph,
United States pharmacopoeial convention, Rockville, MD

11. Freeman M, Hawkins PA, Loran JS, Stead JA (1979) J Chromatogr 2 2:1305-1317. doi:10.1080/01483917908060139

12. Claes PJ, Busson R, Vanderhaeghe $\mathrm{H}$ (298) J Chromatogr 298:445-457

13. Gambardella P, Punziano R, Gionti M, Guadalupi C, Mancini G, Mangia A (1985) J Chromatogr A 348:229-240. doi: 10.1016/S0021-9673(01)92457-4

14. Anhalt JP (1977) Antimicrob Agents Chemother 11:651-655

15. Maitra SK, Yoshikawa TY, Hansen JL, Nilsson-Ehle I, Palin WJ, Schotz MC, Guze LB (1977) Clin Chem 23:22752278

16. Peng GW, Gadalla MAF, Peng A, Smith V, Chiou WL (1977) Clin Chem 23:1838-1844

17. Seidl G, Nerad HP (1988) Chromatographia 25:169-171. doi:10.1007/BF02316439

18. Kaale E, Leonard S, Van Schepdael A, Roets E, Hoogmartens J (2000) J Chromatogr A 895:67-79. doi:10.1016/S00219673(00)00412-X

19. Kaale E, Van Goidsenhoven E, Van Schepdael A, Roets E, Hoogmartens J (2001) Electrophoresis 22:2746-2754. doi:10.1002/1522-2683(200108)

20. Samain D, Dupin P, Delrieu P, Inchauspe G (1987) Chromatographia 24:748-752. doi:10.1007/BF02688579

21. Clarot I, Chaimbault P, Hasdenteufel F, Netter P, Nicolas A (2004) J Chromatogr A 1031:281-287. doi:10.1016/j.chroma. 2003.12.032

22. Megoulas NC, Koupparis MA (2004) J Pharm Biomed Anal 36:73-79. doi: 10.1016/j.jpba.2004.05.018

23. Arul J, Abu R (2010) J Pharm Biomed Anal 51:521-531. doi:10.1016/j.jpba.2009. 09.002

24. Curiel H, Vanderaerden W, Velez H, Hoogmartens J, Van Schepdael A (2007) J Pharm Biomed Anal 44:49-56. doi: 10.1016/j.jpba.2007.01.029

25. Adams E, Roelants W, De Paepe R, Roets E, Hoogmartens J (1998) J Pharm Biomed Anal 18:689-698. doi:10.1016/ S0731-7085(98)00214-3

26. Adams E, Hoogmartens J (2004) Curr Top Electrochem 10:63-70

27. Cherlet $M$, De Baere S, De Backer $P$ (2000) J Mass Spectrom 35:1342-1350. doi:10.1002/1096-9888(200011)

28. Li B, Adams E, Van Schepdael A, Hoogmartens J (2006) Rapid Commun Mass Spectrom 20:393-402. doi:10.1002/ $\mathrm{rcm} .2317$

29. Heller DN, Clark SN, Righter HF (2000) J Mass Spectrom 35:39-49. doi:10.1002/ (SICI) 1096-9888(200001)

30. Manyanga V, Grishina O, Yun Z, Hoogmartens J, Adams E (2007) J Pharm Biomed Anal 45:257-262. doi:10.1016/ j.jpba.2007.06.015

31. Grahek R, Zupancic-Kralj L (2009) J Pharm Biomed Anal 50:1037-1043. doi: 10.1016/j.jpba.2009.06.004

32. Dixon RW, Peterson DS (2002) Anal Chem 74:2930-2937. doi:10.1021/ac0112081 
33. Gamache PH, McCarthy RS, Freeto SM, Asa DJ, Woodcock MJ, Laws K, Cole RO (2005) LCGC N Am 23:150-155

34. Moreau RA (2006) Lipids 41:727-734. doi:10.1007/s11745-006-5024-7

35. Inagaki S, Min JZ, Toyo'oka T (2007) Biomed Chromatogr 21:338-342. doi: 10.1002/bmc. 751

36. Dixon RW, Baltzell G (2006) J Chromatogr A 1109:214-221. doi:10.1016/ j.chroma.2006.01.021

37. Sun $P$, Wang $X$, Alquier L, Maryanoff CA (2008) J Chromatogr A 1177:87-91. doi:10.1016/j.chroma.2007.11.035
38. Blazewicz A, Fijalek Z, Warowna-Grzeskiewicz M, Jadach M (2010) J Chromatogr A 1217:1266-1272. doi:10.1016/ j.chroma.2009.12.025

39. Blazewicz A, Fijalek Z, Sarna K, Warowna-Grzeskiewicz M (2010) Chromatographia 72:183-186. doi:10.1365/ s10337-010-1623-9

40. Vehovec T, Obreza A (2010) J Chromatogr A 1217:1549-1556. doi:10.1016/ j.chroma.2010.01.007

41. International Conference on Harmonization (ICH), Topic Q2 (R1) (2005) Validation of analytical procedures: text and methodology, Geneva. www.emea.europa. eu/pdfs/human/ich/038195en.pdf

42. Forsatz B, Snow N (2007) LCGC N Am 25:960-968

43. Vervoort N, Daemen D, Török G (2008) J Chromatogr A 1189:92-100. doi:10.1016/ j.chroma.2007.10.111 